\title{
Educational Institution Intranet Zone: Scalability to Cloud
}

\author{
Nidhi Srivastava, PhD \\ AlIT \\ Amity University
}

\author{
Rajiv Pandey, PhD \\ AlIT \\ Amity University
}

\begin{abstract}
Cloud computing is an extension of distributed computing where the servers and other services are provided in the cyber space. It gives a flexible platform to increase computing, storage and network power on any device. Cloud computing can be used by an organization to increase its strategical and organizational capabilities. This paper explores the benefits an educational institute can have by shifting from the traditional intranet system to a cloud based intranet system. The paper gives a cloud based Intranet architecture which will effectively and efficiently manage and also meet the demands of the users of this system.
\end{abstract}

\section{Keywords}

Cloud computing, Intranet, IAAS, PAAS, SAAS

\section{INTRODUCTION}

Education institution of today are geographically separated but the academic need demands the stakeholders to be connected $24 * 7$ thus the need is felt to own a customized net zone using internet as a backbone. Most education institutions therefore own an Intranet which is accessible to all stake holders i.e. promoters, academic administrators, faculty and students both in and off campus. Intranet system primarily consists of both the hardware and software, stationed in the campus, managed and paid by the organization and is explained in section II. On the contrary cloud computing
PAAS as a good option for the Institutes to opt for as it gives flexibility both to the providers and the institutes. Finally Section VIII gives the conclusion.

\section{INTRANET SYSTEMS}

Intranet is a network which is used by any organization for its internal working and it is used only by organization's authorized members. The organization can be a company, a society, an educational institution, etc. Intranet helps the employees of the organization who are based in different locations to communicate easily with each other. Intranet helps in storing of the information, their display and also the exchange of information. Also it is helpful in the overall efficiency of the organization and enables office to go paperless [1]. Intranet helps in the horizontal and vertical communication between the employees and all users as authorized by administration on the basis of privileges assigned by the intranet administrator. Intranet is used in various purposes for conveying information to the members of the organization like mailing system, newsletter, group discussion, libraries, downloadable documents, forms, etc. [2, $3]$.

\section{A TRADITIONAL EDUCATIONAL INTRANET SYSTEM}

Intranet can help a lot in the educational system as it will be convenient to exchange information among employers,

\begin{tabular}{|c|c|c|}
\hline $\begin{array}{l}\text { Presentation Tier } \\
\text { - Client side presentation } \\
\text { - Validation Application }\end{array}$ & $\begin{array}{l}\text { Business Tier / Application Server } \\
\text { - Security features like firewall } \\
\text { - Virus protection utilities }\end{array}$ & $\begin{array}{l}\text { Database Tier / Database Server } \\
\text { - Data related to Institute all at one } \\
\text { place }\end{array}$ \\
\hline
\end{tabular}

Figure 1: Traditional Educational Intranet Architecture

offers different resources like servers, network, etc. to be shared over the internet. It is the choice of the consumer that to what extent and for what duration they wish to use the services offered on cloud by the provider. This paper explores the issues with the traditional intranet system on which the educational systems runs and proposes the cloud architecture of intranet system as the solution which has the advantage and looks to overcome the bottlenecks of the traditional system. This paper has seven sections. Section I gives the introduction, Section II defines intranet and lists its uses. Section III explains at length the traditional educational intranet architecture being used by the institutes at present. Section IV defines what cloud is and the different services offered by the cloud services. Section V lists the advantage or the need of cloud architecture over the traditional architecture. In Section VI we have proposed a cloud based Intranet Architecture for Educational Institutes. Section VII suggests faculty, staff, parents and students. Figure 1 describes the traditional intranet system architecture of an educational institution listing its components and its functionality:

\subsection{Presentation Tier}

The client interface layer available to the users enables interface with the system. It shows all the features presented to the users for their use. The good part about this layer is that the view for different users is different. A particular user can see only those details which have been allocated to it by the administrator. In short it gives a client side presentation and also validates the application. Typical users of this system are VC/ProVC, HoD's, faculties, students, parents, staff, academic administrators and prospective students. Each of these users accesses the Intranet for receiving and uploading the information related to them only. Some of the user dependent functionalities are: 
- ProVC $-\mathrm{He} / \mathrm{she}$ can view the entire dataset. The details of the faculties, staff, and students can be seen. The summarized report of the examination results, number of faculties in each department, time in and out of the faculties, their publications, ongoing seminars and conferences in a particular campus and in a specific department, ongoing research work and project, etc. can be viewed.

- Faculty - Can view their daily classes and mark attendance. Maintain their personal data like educational and professional qualifications, work experience, publications, etc. They can view their office in timings and out timings, leave status, feedback given by the students, etc. Notes and study materials for the benefit of the students are uploaded by them. Also any problem with the software can be reported. Intranet mailing system helps in exchange of information between the faculties and the organization. Faculties can also see the availability and then book the auditoriums or conference halls as per their requirement.

- $\quad$ Students - Can view time table, attendance and also the materials uploaded by the faculties. All the forms like examination, registration, etc. is available on the Intranet for the students to download and use. Students can also view the details of the faculties who will be teaching a particular subject to them. They can give feedback of each faculty.

- Parents - Can view the details of their ward. The mark sheet for all semester is available along with the attendance. This can help the parents in keeping a track of their ward. Further they can also view the faculties who are teaching them which course. Also they can interact with the faculty through the email system for the performance of their child or for any other information.

- $\quad$ Staff - Different staff members of different departments eg. HR, admin, academics, etc. can store their details and also generate reports from the data stored. eg. admin staff can get to know that who has booked the auditorium or conference hall on which date and at what time and thus can make the required arrangement for the same. Same way the HR department has the time in and time out of the faculty so can maintain their leaves and salary, etc. As each faculty maintains their details on the intranet, it is possible for HR to get the details like publications and experience of the faculties easily from the Intranet.

- Academic Administrators -- Maintains the data of the organization on the Intranet like displaying of the time table and editing it. Further, they can prepare report on the data stored with respect to faculties, students or staff, etc. Some of the reports that can be generated are like the publication details of the faculties, the analysis of the result of the students, a summary of the students with less attendance. Also, the number of classes held, not held and attendance marked or not marked and the reason for the same can be generated through the system..

\subsection{Business Tier}

Business rules with respect to identity management and user protection are incorporated into the business tier. As the system contains very informative, important, crucial and confidential data its security and protection are very essential.
To enable data protection each of the users is given a separate username and password through which they can interact. In fact the access given to the different users are different. This means that the person at higher authoritative level can view the data of the people who are subordinate in the hierarchy with respect to them eg. HODs can view the details of the faculties and the students in their institutions. Similarly, ProVC can view the data of the faculties, students and staff of the whole educational institute. The system should have a firewall technology so that the illegal IP users are unable to access the system. Further, for prevention from viruses, the system should use virus protection utilities. Further more restrictions can be applied so that there is no loss of data and the hackers are unable to penetrate into the system.

\subsection{Database Tier}

This is the important of all the layers as all the datasets are stored here. The typical data available and stored are the details of students, faculty, and staff of all institutions across all the campuses. The details such as student's enrollment no., name, address, course, etc. faculty's name, qualification, work experience, publications, etc. are stored. Also the attendance of students and in and out time of the faculties is stored. This is very large as it contains all the data which can be used at any time by anyone who is using the system.

\section{CLOUDS \& ITS SERVICES TO SUPPORT INTRANET SYSTEMS}

As the data is growing exponentially nowadays we have moved from earlier measurement of data in kilobytes or megabytes to zettabyte. Managing such huge data is really becoming a problem. To manage such data is not easy and thus the smart way now is to move to cloud computing. In fact cloud computing has changed the way information technology was being used by different organizations till now. [4]

IEEE Computer Society defines Cloud Computing as: "A Paradigm in which information is permanently stored in servers on the Internet and cached temporarily on clients that include desktops, entertainment centers, table computers, notebooks, wall computers, handhelds, etc."

Cloud computing offers three layers of abstraction depending on the extent of usage of the services and applications on cloud. These three layers are IAAS, PAAS, SAAS.

- IAAS (Infrastructure as a Service) - In this the basic infrastructure that is the application, database and OS is that of users whereas the server, storage and network, etc. are on cloud and can be accessed from anywhere eg. virtual machine. It is the responsibility of the service providers to run and maintain the services given by him and the consumer has very limited or no control over the services provided by the service providers. [5]

- $\quad$ PAAS (Platform as a Service) - In this the user keeps only the application with himself and rest all the infrastructure like database, OS, server, storage, network, etc. are on the cloud. The service provider as compared to IAAS has a greater control on the cloud infrastructure, whereas the consumer has some control over the deployed application. [6]

- $\quad$ SAAS (Software as a Service) - In this all the resources are kept on the cloud and the user only uses or consumes these resources using Internet. Basically the provider runs the application on the cloud and the services are provided to the consumer eg. email services. This is a 
benefit as all users will now access the same software and also the administration of the services is easy $[5,6]$.

Different types of cloud are available for the organization to opt from. They are:

- Public Cloud: It is for the general public and any one can use it be it individual user, academic institutions, government and private organizations, etc. Services for the cloud are provided by an external agency. There are many users but still each of the users is given security so that their data remains safe and secure.

- Private Cloud: Also known as internal cloud. As the name suggests, it is privately used by an organization for its many customers. Private cloud can be maintained by the organization itself or by any external agency. It can exist anywhere on the campus or off the campus.

- Hybrid Cloud: It is a combination of public and private cloud. Few of the services are run on public cloud and rest on private. This is done so as to take the best features of both the clouds and avoid the limitations of the two. Generally for critical activities private cloud is used and for non-critical activities public cloud is used. [6, 3, 7]

\section{NEED TO MIGRATE TO CLOUDCOMPUTING}

We can see from the above discussion that the dataset of any educational institution is very large as it includes the contents to serve so many actors or users.

With the changing times and needs of the student most of the academic institutions have started catering to both in-campus and off-campus students therefore the data size is not only growing in volume but also adding Big Data features like velocity, complexity, veracity, etc. Off campus student demands his lectures to be available $24 * 7 * 365$ and wishes to mostly interact through social media. These compressing demands make the academic organization to port the dataset from and intranet environment to a cloud environment.

Contents of the institutional database are:

- Day to day lesson plan and session plan.(high end Audio and Video simulated contents)

- Different presentations, notes and lectures for the students. In short presentations and simulations to assist teaching and learning.

- Details of the students like name, fathers name, address, enrollment no., educational qualification, marks, etc.

- Time in and time out of the faculty and staff.

- Feedback from the students about the faculty.

- Details of the faculty like name, educational qualification, professional qualification, work experience, publications, research students, etc.

- Details of the different activities being conducted in the campus or off campus like seminars, workshops, conferences, etc.

- Availability of the different information for all users like digital library, notice board, list of holidays, $R \& D$ data, etc.
- $\quad$ Also daily news \& events, upcoming events and notices are displayed for everyone to view.

- $\quad$ Still many more data is stored.

The above features multiply the volume and also classify as big data. The storage and day to day analysis on such a dataset becomes challenging thus, an organization is forced to look for cloud options.

The cloud architecture model given in fig. 2 renders an organization all advantages of Cloud like reduction in operational cost, hard ware and software scalability, overcoming bottlenecks with respect to network transfers.

The benefit of using the cloud architecture over the traditional system can be listed as follows:

1. Easy access of data from anywhere and from any device. Since the data resides on the cloud it is available to all the campuses of the institution through any device eg. mobile, tablets, laptops, PCs, etc.

2. Accessing of the data is so easy and efficient that the user has a feel that their data is located locally whereas in actual the data is somewhere on the cloud several miles away.

3. The cloud architecture can help them in easy access and maintenance of the data on the clouds and also there is unlimited storage capacity.

4. When the services are on cloud the cost is effectively reduced as now the data centers hold all the data. The infrastructure cost per compute or the application cost per end-user is drastically reduced [7].

5. Another advantage of cloud is that an organization can scale the applications according to the demand of the users. So, scalability can be applied to the resources like network, servers, storage, etc. so that on demand they can be expanded or contracted.

6. The backup and recovery of the data is now not a headache of the organization but that of the service providers. Although for each of the server a backup server will have to be maintained so that in case of failure the data can be fully recovered but the way of maintenance on the cloud is easy and very effective.

Thus, cloud computing comes in here which will with time easily handle this amount of data and more importantly the data will be available to any authorized person from anywhere using any device. A good advantage of using cloud computing will be that distance learning can be implemented in a good way. Thus, extending distance learning curriculum to mooc environment will lead to huge video \& simulation contents

\section{A SUGGESTIVE ARCHITECTURE ON THE CLOUD}

It is beneficial for an educational institution to move from traditional computing to cloud computing as it is readily available and is also scalable. An architecture that these educational institutions can follow on cloud is as shown in figure 2 . 


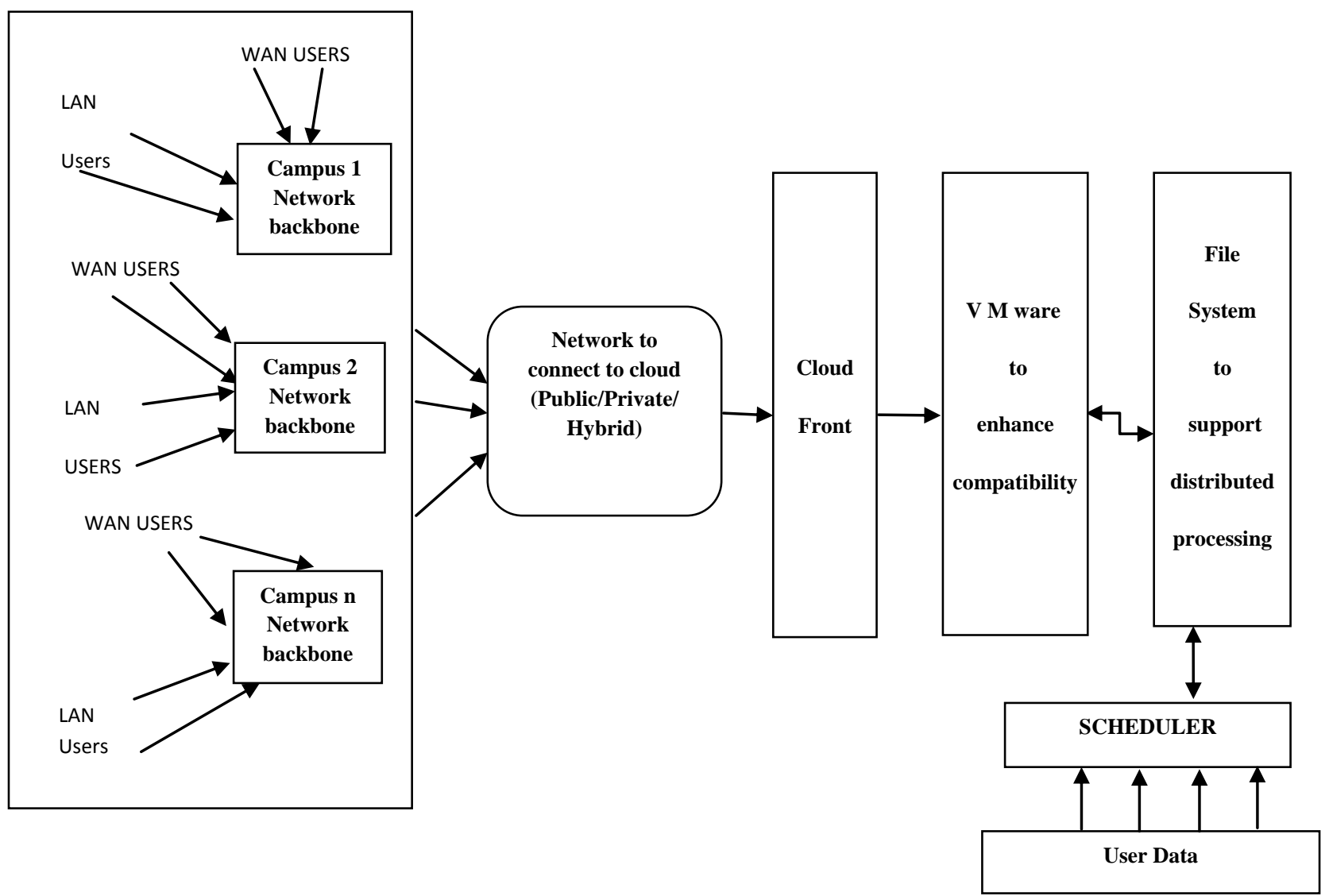

Fig 2: Cloud based Intranet Architecture for Educational Institutes

An institutional organization can have its campus at different locations within the city or in different states or countries. Each of these campuses needs to communicate within the campus and also across the campuses for exchange of information between them.

In this through LAN or Wifi connection different users can connect to their campuses for all types of information. Each of the campus through a network in turn connects itself to the cloud infrastructure for data access. This network can be a leased line or open internet connectivity. The cloud infrastructure has a cloud front which is the data center containing all the dataset as discussed above.

After accessing the cloud front, the data passes through the VMWare. This Virtualization Machineware can be a lot of help in the cloud computing. The Institutes can make use of virtualization of operating system, networks, storage devices, applications or servers. Special software is used in virtualization, which helps in running a virtual system. A virtual system is one in which on a single server, multiple operating systems and multiple applications can run. Thus, any system is flexible to interact with the machine irrespective of the OS it is using. This leads to greater flexibility and agility. Virtualization reduces the operational cost and maintenance cost also. $[8,9,10]$

After this virtualization layer, there exists a file system which supports the distributed processing. This is linked with a scheduler. The job of the scheduler is to manage the job in this distributed system by dividing the job between each of the systems for fast and effective operation. All the management of the scheduling for the job is done by the scheduler. The cloud infrastructure has a cloud front which is the data center containing all the dataset as discussed above. The institutional organizations can deploy any one of the models among IAAS, PAAS and SAAS depending on what type of services it wants to keep to itself and what services it wants on the cloud. For example if SAAS model is adopted by the organization then all the services like infrastructure, software application, etc. are maintained on the cloud. So, the database tier or database along with business tier or all three tiers can be put on the cloud. Further it is up to the institution if they wish to use private or a hybrid (both public and private) cloud for the services. Thus, we see that this cloud architecture system has many advantages over the traditional computing system and overall it will prove to be beneficial for the educational institutions to shift to the cloud environment

\section{IAAS Vs PAAS}

Section IV has explored three layers of abstraction offered by cloud computing. IaaS and PaaS are the viable options for the educational institutes to adopt. Prime factors influencing the decision for selection of IaaS OR PaaS are:

- Dynamicity of the data

- Frequency of In-house amendments

- Availability of Hardware and Software

- Operational cost of the Hardware and Software.

- Licensing and legal issues of softwares involved

- Updates of the softwares and patches.

- Obsolete cost of the hardware.

Factors obvious in a contemporary institutional environment are: 
- Data is dynamic in educational institutes as the information keeps on changing.

- Needs regular updates with respect to student information, class schedules, extra classes, etc.

- Since possession and running costs are high, institutions desire for a cheap solution.

- High and varying student intake calls for large no of software license which is financially and legally expensive.

\begin{tabular}{|c|c|c|}
\hline IaaS & \multicolumn{2}{|c|}{ PaaS } \\
\hline \multirow{2}{*}{ Managed by } & Data & Managed by \\
\hline & Applications & Institutes \\
\hline \multirow[t]{2}{*}{ Institutes } & Runtime & \multirow{7}{*}{ Managed by } \\
\hline & Middleware & \\
\hline \multirow{5}{*}{ Managed by } & $\mathrm{O} / \mathrm{S}$ & \\
\hline & Virtualization & \\
\hline & Servers & \\
\hline & Storage & \\
\hline & Networks & \\
\hline
\end{tabular}

Figure 2: Iaas Vs. PaaS

Figure 3 lists the various applications and infrastructure managed in IaaS and PaaS by the providers and by the Institutes. In PaaS the institute controls the data and applications whereas the rest all the services are controlled by the providers, whereas in IaaS along with data and applications, the institutes also need to manage middleware.

PaaS gives flexibility to the institute to manage their work and it also helps institute to enhance and attain customization at their organization end for example the institutes can put their daily schedule, any important deadlines, details of conferences and seminars being conducted on a specific date, etc. The front end data is very dynamic in an educational institution thus in house amendments are the most suited options. Thus, with reference to the needs of the educational institutes and the presence of the above given factors in an institution, and the control required by the institutes $\mathrm{PaS}$ seems to be a better choice than IaaS although, it is at the sole discretion of the institute to opt from any of the three, depending on the cost, utility and management of resources.

\section{CONCLUSION}

Cloud has brought revolution in the field of IT industry. In this paper we discussed that how intranet is useful for the educational institutions. The current traditional intranet architecture system being followed in the institutes is presented. There is a high need for the educational institutes to shift from this traditional system to the cloud architecture as it is beneficial and is more advantageous. All the benefits of the cloud computing are listed and explained in the paper. A new architecture which the educational institutes can follow on the cloud is given which will render all the benefits of the cloud to the institutes. The advantages like scalability, large data storage, easy access and maintenance, low cost, etc. will definitely improve the performance of the system and give an edge above the traditional system. After studying and analyzing the needs of the Institutes, PAAS seems a good option for the educational institutes to adapt.

\section{REFERENCES}

[1] Lai V.S. 2001. Intraorganizational communication with Intranets: Communications of the ACM, Vol. 44, No. 7, 95- 100 .

[2] Chang Ling-E, Lin Shang-Ping 16-18 May 2011. Newcomers' Socialization by Intranet System 10th IEEE/ACIS International Conference on Computer and Information Science, Sanya, China, 239-243.

[3] P.Bindu Shamily, S. Durga December 2012. A review on Multimedia Cloud Computing, its advantages and challenges IJARCET, Vol. 1, No. 10, 130-133.

[4] Mishra N., Khushwha K., Chasta R., Choudhary March 2013. Technologies of Cloud Computing - Architecture Concepts based on Security and its Challenges IJARCET, Vol. 2, No. 3, 1143-1149.

[5] Meher N. K., Lokhande S.P.: Cloud Computing March 2013. An Architecture, its Security Issues \& Attacks IJARCET , Vol. 2, No. 3, 884-890.

[6] Olekar G., Sreekumar V. March 2013. Cloud Computing: Migration from Traditional Systems to the Cloud IJARCET, Vol. 2, No. 3, 1128-1131.

[7] CISCO, 2010. Cloud: Powered by the Network, What a Business Leader Must Know. www.cisco.com/web/strategy/docs/gov/cloud_wp_c11_6 09220.pdf

[8] Sina M., Sadra Mohammadalian, Nur Izura Udzir, Azizol Abdullah 2012. Secure Model for Virtualization Layer in Cloud Infrastructure, IJCSDF Vol 1, No. 1, 32 -40.

[9] Lena A., Soha S. Z... Jan 30 - Feb 1st, 2013A New Virtualization-Based Security Architecture in a Cloud Computing Environment The Third International Conference on Digital Information Processing and Communication, Dubai, 676-686.

[10] Yoshio M., Yoshiro I. 2015. Development of an Integrated Information Server System for IT Education through Server Virtualization Technology IJNCAA Vol.5 No. 1, 39-47. 